\title{
Clinicopathological Characteristics and Survival Status of Male Breast Cancer, a Single Center Experience
}

\section{Seyed Mostafa Shiryazdi ${ }^{1}$, Nazila Abrishami ${ }^{1,2}$, Mohammad Forat-Yazdi ${ }^{3}$, Seyed Mohammad Reza Mortazavizadeh ${ }^{3}$, Hossein Neamatzadeh ${ }^{4}$}

${ }^{1}$ Department of General Surgery, Shahid Sadoughi University of Medical Sciences, Yazd, Iran. ${ }^{2}$ Mother and Newborn Health Research Center, Shahid Sadoughi University of Medical Sciences, Yazd, Iran. ${ }^{3}$ Department of Internal Medicine, Shahid Sadoughi University of Medical Sciences, Yazd, Iran. ${ }^{4}$ Mother and Newborn Health Research Center, Shahid Sadoughi University of Medical Sciences, Yazd, Iran.

\begin{abstract}
Background and objective: Male breast cancer is a rare condition and its underlying mechanism is not well understood. Therefore, we conducted this study to find out the clinicopathological characteristics of a series of male breast cancer consecutively treated in Yazd, Iran, over a 15-year period. Material and method: We retrospectively analyzed clinicopathological characteristics using a cohort of 39 male breast cancer patients who were surgically treated at the Shahid Sadoughi Hospital, Yazd, Iran, between 2001 and 2016. The demographic data, age, histology, disease stage, hormone receptor (HR) status, overall survival status, surgery treatment procedures, adjuvant treatment, and tumor stage were registered. A total of 39 male breast cancer patients were included. Results: The median age at diagnosis was 57.92 years (range, 21-95 years). Eight patients (20.5\%) had family history of breast cancer. The collective 2-, 5-, and 10-year survival in our cohort was $83.4 \%, 43.2 \%$, and $10.3 \%$, respectively. The disease stage was significantly associated with overall survival $(\mathrm{p}=0.001)$. Conclusion: In our cohort, survival rates as well as the median age at diagnosis were lower than those reported in previous reports. Moreover, the disease stage was a main independent prognostic factor for survival.
\end{abstract}

Keywords: Male breast cancer- clinicopathological- survival- histology- adjuvant treatment

Asian Pac J Cancer Biol, 2 (4), 95-100

\section{Introduction}

Breast cancer is the commonest cancer in women [1-2]; however, it is also seen in men with peaks at age 71 years [3]. In men, the prevalence of breast cancer is less than $1 \%$ of all malignancies and also $1 \%$ of all breast cancer cases worldwide. Approximately 2000 male breast cancer cases are diagnosed annually in the United States, but the incidence appears to be increased over the past 30 years [4]. Different tests and devices are used for screening and diagnose of breast cancer in women [5], but currently indications for male breast cancer screening are lacking [6-7]. Due to rarity of male breast cancer, the underlying mechanism is not well understood [8]. The degree of similarity between breast cancer in males and females has not been well understood yet. It seems that male breast cancer behaves in a similar way to
Submission Date: 09/11/2017 Acceptance Date: 11/25/2017

postmenopausal female breast cancer [9-10]. Establishing the precise risk factors for male breast cancer has been challenging due to the rarity of the disease among this population. However, the risk factors identified to date include family history of breast and ovarian cancer and a known genetic predisposition due to mutations in the BRCA2 gene. Women carrying mutations on BRCA1 and BRCA2 have a lifetime breast cancer risk of $45-65 \%$ [11-13]. While male breast cancer familial cases usually have $\mathrm{BRCA} 2$ rather than BRCA1 mutations.

Clinicopathological characteristics of male breast cancer in most developed countries have been unveiled. The recent trends in the male breast cancer have showed that there are limited data and also controversies in term of characteristics, management, survival and treatment of male breast cancer in Iran [14-15]. Therefore, we performed this study to survey the clinicopathological

Corresponding Author:

Dr. Nazila Abrishami

General Surgery, Shahid Sadoughi University of Medical Sciences, Yazd, Iran.

Email: n.abrshami@gmail.com 
characteristics and survival status of male breast cancer using a cohort with 39 male breast cancer patients who consecutively treated in Yazd, Iran, over a 15-year period.

\section{Materials and Methods}

Approval from the local ethics committee of Shahid Sadoughi Hospital, Yazd, Iran, was obtained prior conducting the study. The data on male breast cancer patients treated surgically at the Shahid Sadoughi Hospital, Yazd, Iran, between 2001 and 2016 were retrospectively reviewed. The patients' demographic and clinicopathological characteristics such as age, histology, disease stage, hormone receptor (HR) status, overall survival status (if not recorded interviewed by telephone), and TNM staging were registered. The 2-, 5- and 10-year survival was estimated. In this retrospective study, the overall survival was defined as the time of death due to any reason. In addition, the staging was made according to American Joint Committee on Cancer. Breast immunohistochemical staining was used to examine estrogen receptor (ER) or progesterone receptor (PR) and human epidermal growth factor receptor 2 (Her2). In addition, the surgical procedures, adjuvant chemotherapy, radiotherapy, and hormonal therapy were recorded.

\section{Statistical analysis}

All statistical analysis was performed using SPSS (version 19, SPSS, Inc, Chicago, IL, USA) and $p$ value less than 0.05 was considered to indicate a statistically significant difference. In this study, the categorical and continuous variables were summarized using descriptive statistics (e.g., median, range, frequency, and percentage). Chi-square test was used for categorical data and the Student's t-test for continuous data. In addition, the overall survival was calculated using Kaplan-Meier methods (log-rank test).

\section{Results}

A total of 39 male breast cancer patients were diagnosed and treated in our hospital over 15 years from 2001 to 2016. The patient's clinicopathological characteristics such as tumor size, histopathological types, tumor grade, lymph node infiltration, and HR status are shown in Table 1 . The median age of the patients was 57.92 years (ranged from 21 to 95 years) with a peak age of 60-69 (33.3\%) years.

The main histological subtypes in the cohort were invasive ductal $(84.6 \%)$, comedocarcinoma $(5.1 \%)$, invasive papillary carcinomas (5.1\%), malignant fibrous histiocytoma $(2.6 \%)$, and tubular carcinoma $(2.6 \%)$. All patients underwent surgery and modified radical mastectomy (MRM) (71.8\%), biopsy (20.5\%), partial mastectomy $(2.6 \%)$, lymph node biopsy $(2.6 \%)$ were most commonly performed surgical procedures in this cohort, respectively. The majority of our cohort (38.5\%) were in stage II (IIA and IIB), followed by stage III (IIIA and IIIB) (30.8\%), IV stage (17.9\%), and stage IA (7.7\%).

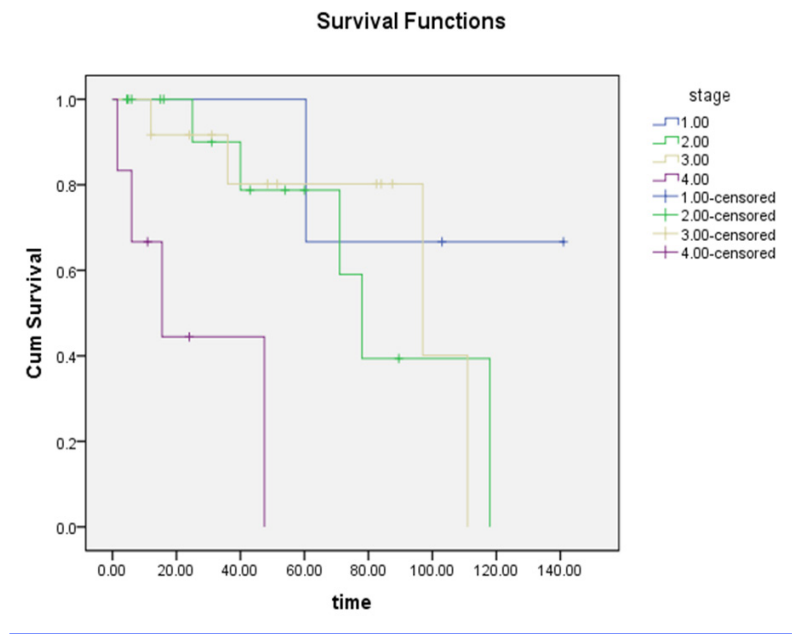

Figure 1. Overall Survival in the Cohort

Immunohistochemistry (IHC) staining was performed in $27(69.2 \%)$ out of 39 patients. ER, PR, and HER2 were positive in $85.2 \%, 77.8 \%$, and $25.9 \%$ of the tumors, respectively. Eight male breast cancer patients $(20.5 \%)$ had family history of breast cancer while 10 cases $(25.7 \%)$ had family history of other malignancies. Cardiovascular disease was the most frequent chronic disease in our cohort (28.2\%). The blood group type was available for 29 male breast cancer patients. The distribution of blood groups in the cohort $(\mathrm{n}=29)$ was $11(37.9 \%)$ blood group $\mathrm{O}$, 7 (24.1\%) blood group A, 8(27.6\%) blood group B, and $3(10.3 \%)$ blood group AB.

A total of 36 male breast cancer patients were enrolled in our survival analysis study. Table 1 demonstrates the survival results of the cohort. In addition, the Kaplan-Meier curve for overall survival is shown in Figure 1. The collective 2-, 5- and 10-year survival in our cohort was $83.4 \%, 43.2 \%$, and $10.3 \%$, respectively. The disease stage significantly associated with overall survival $(p=0.001)$. Additionally, the five-year overall survival was $114.16 \pm 21.90$ in patients in stage $I, 82.79 \pm 13.53$ in patients in stage II, $88.54 \pm 12.28$ in patients in stage III, and it was $25.80 \pm 9.96$ in patients in stage IV. There was a significant difference in overall survival with respect to disease stages $(\mathrm{p}=0.001)$.

\section{Discussion}

There is increasing evidence suggesting that male breast cancer molecularly and clinically is a heterogeneous condition which differs from those seen in women. However, the rate of presentation in advanced stage breast cancer has been decreasing in men and women [16]. There are a few studies evaluated the clinicopathological characteristics and risk factors of male breast cancer in Iranian population. Therefore, we conducted the current study to survey the clinicopathological characteristics of male breast cancer using a cohort with 39 cases who consecutively treated in Yazd, Iran, over a 15-year period. 
Table 1. Baseline Clinicopathological Features of 39 Male Breast Cancer Patients

\begin{tabular}{|c|c|c|}
\hline Feature & & Frequency $(\%)$ \\
\hline Histopathology & $\begin{array}{c}\text { Invasive Ductal Carcinoma } \\
\text { Comedocarcinoma } \\
\text { Invasive Papillary Carcinoma } \\
\text { Malignant Fibrous Histiocytoma } \\
\text { Tubular Carcinoma }\end{array}$ & $\begin{aligned} 33 & (84.6) \\
2 & (5.1) \\
2 & (5.1) \\
1 & (2.6) \\
1 & (2.6)\end{aligned}$ \\
\hline Side & $\begin{array}{c}\text { Right } \\
\text { Left }\end{array}$ & $\begin{array}{l}22(56.4) \\
17(43.6)\end{array}$ \\
\hline Type of surgery procedure & $\begin{array}{l}\text { Modified Radical Mastectomy } \\
\text { Biopsy } \\
\text { Partial Mastectomy } \\
\text { lymph node biopsy } \\
\text { Others }\end{array}$ & $\begin{array}{c}28(71.8) \\
8(20.5) \\
1(2.6) \\
1(2.6) \\
1(2.6)\end{array}$ \\
\hline Stage* & $\begin{array}{c}\text { I (IA) } \\
\text { II (IIA,IIB) } \\
\text { III (IIIA,IIIB) } \\
\text { IV } \\
\text { Missing }\end{array}$ & $\begin{array}{c}3(7.7) \\
15(38.5) \\
12(30.8) \\
7(17.9) \\
2(5.1)\end{array}$ \\
\hline Hormone-receptor status & $\begin{array}{c}\text { HER2+ } \\
\text { PR+ } \\
\text { ER+ }\end{array}$ & $\begin{array}{c}7(25.9) \\
21(77.8) \\
23(85.2)\end{array}$ \\
\hline & $\mathrm{O}+$ & $11(37.9)$ \\
\hline D1pod arouna $(n-20)$ & $\begin{array}{l}\mathrm{A}+ \\
\mathrm{A}-\end{array}$ & $\begin{array}{c}6(20.7) \\
1(3.4)\end{array}$ \\
\hline Blood groups (n=29) & $\begin{array}{l}\mathrm{B}+ \\
\mathrm{B}-\end{array}$ & $\begin{array}{c}6(20.7) \\
2(6.9)\end{array}$ \\
\hline & $\mathrm{AB}+$ & $3(10.3)$ \\
\hline Family history of a malignancy & $\begin{array}{l}\text { Breast cancer } \\
\text { Ovarian cancer } \\
\text { Colon cancer } \\
\text { Others }\end{array}$ & $\begin{array}{c}8(20.5) \\
1(2.6) \\
1(2.6) \\
10(25.7)\end{array}$ \\
\hline Chronic disease & Cardiovascular disease & $11(28.2)$ \\
\hline & $\begin{array}{c}\text { Diabetes } \\
\text { Thyroid } \\
\text { Other }\end{array}$ & $\begin{array}{c}6(15.4) \\
3(7.7) \\
12(30.8)\end{array}$ \\
\hline Vital status & $\begin{array}{c}\text { Alive } \\
\text { Dead } \\
\text { Missing }\end{array}$ & $\begin{array}{c}24(61.5) \\
14(35.9) \\
1(2.6)\end{array}$ \\
\hline Chief complaint & $\begin{array}{c}\text { lump } \\
\text { Nipple discharge } \\
\text { Nipple retraction } \\
\text { Pain }\end{array}$ & $\begin{array}{l}17(43.6) \\
10(25.6) \\
7(17.9) \\
5(12.9)\end{array}$ \\
\hline Adjuvant treatment $(\mathrm{n}=34)$ & $\begin{array}{c}\text { Chemotherapy } \\
\text { Hormone therapy } \\
\text { Radiotherapy } \\
\text { Chemotherapy + Hormone therapy } \\
\text { Chemotherapy + Hormone therapy + Radiotherapy }\end{array}$ & $\begin{array}{c}7(20.5) \\
8(23.5) \\
1(2.9) \\
4(11.7) \\
14(41.2)\end{array}$ \\
\hline
\end{tabular}

*American Joint Committee on Cancer (7th edition)

Table 2. Survival Status in the Cohort

\begin{tabular}{lcc} 
& Median $($ Mean \pm SD) & Percent \\
\hline All survival & $82.75 \pm 9.22$ & 61.1 \\
2-years survival & $99.40 \pm 78.21$ & 83.4 \\
5-years survival & $93.40 \pm 91.08$ & 43.2 \\
10-years survival & $113.57 \pm 14.14$ & 10.3 \\
Stage (OS)* & & \\
I (IA) & $114.16 \pm 21.90$ & 66.7 \\
II (IIA,IIB) & $82.79 \pm 13.53$ & 66.7 \\
III (IIIA,IIIB) & $88.54 \pm 12.28$ & 66.7 \\
IV & $25.80 \pm 9.96$ & 33.3 \\
\hline
\end{tabular}

$* \mathrm{P}=0.001$ 
Age at the diagnosis is one of the main prognostic factors which significantly affected the survival of the male breast cancer patients $[17,18]$. In our cohort, the median age at diagnosis was 57.92 years, comprising youngest population in comparison with other published series in the west or developed countries. However in a case series on 69 Egyptian male breast cancer patients, the median age at diagnosis was 58 years [19]. In a cohort from 42 Indian patients, the median age was 56 years [18]. In two case series from Iranian male breast cancer patients, the median age at diagnosis was reported 49.24 and 60.3 years $[14,15]$.

Today, most male breast cancer patients undergo modified radical mastectomy with axillary lymph node dissection or sentinel node lymph biopsy [4, 10]. This procedure is less invasive than a radical mastectomy, which was the standard treatment for localized male breast cancer for most of the 20th century [9]. However, there was no significant difference between radical mastectomy and other methods in terms of survival. In this cohort, most cases were undergone modified radical mastectomy. Recently, in a case series on 39 Egyptian male breast cancer patients, the majority $(87.2 \%)$ of patients underwent modified radical mastectomy [19]. Similarly, Cutuli et al., performed modified radical mastectomy in $372(76 \%)$ male breast cancer patients in a large cohort [20]. In another study by Yoney et al., the modified radical mastectomy procedure was performed in 59\% of male breast cancer patients but simple mastectomy was conducted in $41 \%$ of cases [21].

According to the previous studies, the proportion of positivity for hormone receptor among male breast cancer patients is between $75 \%$ and $85 \%$, which is higher than women breast cancer patients [22]. In the current study the ER, PR, and HER2 were positive in $85.2 \%, 77.8 \%$, and $25.9 \%$ of the male breast cancer patients, respectively. Similarly, Zeinalian et al. showed that ER, PR and HER2 were positive in $67.8 \%, 48.8 \%$, and $31.8 \%$ of the cases, respectively [23]. Choi et al, reported the proportion of ER and PR positivity as $61.9 \%$ and $56.5 \%$, for men diagnosed with breast cancer, respectively. Moreover, they found that the proportions of ER and PR positivity for men were relatively high compared with those for women [22].

Anderson et al., in a comparative study, revealed that $77.5 \%$ and $92.4 \%$ of breast cancers were ER-positive for female and male, respectively [23]. According to high proportion of hormone receptor positivity findings, the adjuvant hormone therapy after surgical procedures might be effective for male breast cancer patients [24].

A painless lump in the breast is the most common clinical symptom of male breast cancer [25]. In the male breast cancer located in the Retroareolar area, the nipple involvement was a relatively early event, with retraction described in $7-9 \%$ and discharge in $2-6 \%$ of cases [9-20]. In the current study, lump was the main recorded clinical symptom (43.6\%), followed by nipple discharge $(25.6 \%)$. In another Iranian cohort, palpable mass or lump (96.8\%) and nipple discharge $(15.6 \%)$ were the most common symptoms among male breast cancer patients [18]. Epidemiological studies demonstrated that the rate of familial breast cancer in male breast cancer was approximately $15 \%-20 \%$, which was higher (7\%) than that for female breast cancer [4-26]. In addition, it was reported that male breast cancer patients with family history of breast cancer had earlier disease onset than male patients without family history of breast cancer [27]. In our cohort, $20.5 \%$ of cases had family history of breast cancer, which was slightly higher than previous reports.

Several epidemiological studies surveyed the association between ABO blood group and female breast cancer risk [28-29]. However, no study has investigated the distribution of blood in male breast cancer yet. In our cohort, blood type $\mathrm{O}$ was the most frequent blood group. A meta-analysis of 14 studies invoving 9,665 breast cancer patients and 244,768 controls found that Caucasian people with blood type A had higher risk of this cancer than Caucasians with other blood groups [29]. Interestingly, Costantini et al., reported that female breast cancer patients with $\mathrm{O}$ blood type had a significantly lower risk of death than patients with non-O blood types [28].

Therefore, it seems that the distribution of ABO blood group between male and female breast cancer patients is different.

The 2-, 5-, and 10-years survival in our cohort was $83.4 \%, 43.2 \%$, and $10.3 \%$, respectively. Inconsistent with our results, in two other Iranian studies, the 5-years survival was higher than that in our study [14, 15]. Amirifard et al. concluded that the 5-year survival among 17 male breast cancer patients in Kermanshah was 64\% [15]. Salehi et al., found that the 5-year overall survival rate was $66.0 \%$ in a male breast cancer cohort in the South of Iran [14]. Choi et al., showed reported that the 5- and 10 -year overall survivals among 400 Korean male breast cancer treated from 1978 to 2009 were $85.9 \%$ and $70.5 \%$, respectively [22]. In another study, the 5-years overall survival was $68.1 \%$ in 97 male breast cancer patients [30]. Considering previous similar studies, the overall survival in our cohort was shorter than other populations.

The regression analysis indicated that several factors such as gender, age at diagnosis, stage, lymph node status, grade, race, and histology were predictors of overall survival for male and female breast cancer [31].

Our results indicated a significant difference in median survival for patients in stage III disease and stage IV disease $(\mathrm{p}=0.001)$. Similarly, Nahleh et al., found that disease stage was a main overall survival predictor among 612 male breast cancer patients diagnosed between 1995 and 2005 [31].

Surgery is the standard treatment for early stage male breast cancer followed by adjuvant therapy depending on prognostic factors, which is the same as in women [16]. In this cohort, the adjuvant therapy, including hormonal, chemotherapy and radiotherapy was administered for the patient according to their disease stage. The adjuvant hormonal therapy i.e tamoxifen and aromatase inhibitors were the most common treatment in our cohort which was indicated for $23.5 \%$ of receptor-positive tumors, followed by chemotherapy in $20.5 \%$ of patients. Masci et al., 
reported that adjuvant chemotherapy was associated with better overall survival [30]. However, there are several questions in term of the impact of HER-2 positivity on survival and treatment with adjuvant anti-HER-2 therapy [32].

In summary, in our cohort, the median age at diagnosis and survival rates were lower than those reported in previous reports. The disease stage was a main independent prognostic factor for the overall survival. However, we did not analyze other prognostic factors which might significantly affected overall survival in our cohort. Therefore, further studies are required to discover factors affecting breast cancer among males.

\section{Conflict of interest}

The authors declared no conflict of interest.

\section{References}

1. Jafari Nedooshan J KS, Neamatzadeh H, Haghighi F, Dehghani Mohammad Abadi R, et al. Lack of Association of the Fat Mass and Obesity-Associated (FTO) Gene rs9939609 Polymorphism with Breast Cancer Risk: a Systematic Review and Meta-Analysis Based on Case-Control Studies. Asian Pac J Cancer Prev. 2017;;18::1031-7.

2. Kargar S, Shiryazdi SM, Atashi SR, Neamatzadeh H, Kamali M. Urinary Iodine Concentrations in Cancer Patients. Asian Pacific journal of cancer prevention: APJCP. 2017;18(3):819-21.

3. Rudlowski C. Male Breast Cancer. Breast care (Basel, Switzerland). 2008;3(3):183-9.

4. Gomez-Raposo C, Zambrana Tevar F, Sereno Moyano M, Lopez Gomez M, Casado E. Male breast cancer. Cancer treatment reviews. 2010;36(6):451-7.

5. Shiryazdi SM KG, Neamatzadeh H, Kargar S. Health beliefs and breast cancer screening behaviors among Iranian female health workers. Asian Pac J Cancer Prev 2014; ;15::9817-22.

6. Shiryazdi SM, Kargar S, Taheri-Nasaj H, Neamatzadeh H. BreastLight apparatus performance in detection of breast masses depends on mass size. Asian Pacific journal of cancer prevention: APJCP. 2015;16(3):1181-4.

7. Shiryazdi SM, Kargar S, Nasaj HT, Neamatzadeh H, Ghasemi $\mathrm{N}$. The accuracy of Breastlight in the detection of breast lesions. Indian journal of cancer. 2015;52(4):513-6.

8. Ottini L. Male breast cancer: a rare disease that might uncover underlying pathways of breast cancer. Nature Reviews Cancer. 2014;14(10):643.

9. Fentiman IS, Fourquet A, Hortobagyi GN. Male breast cancer. Lancet (London, England). 2006;367(9510):595-604.

10. Ruddy KJ, Winer EP. Male breast cancer: risk factors, biology, diagnosis, treatment, and survivorship. Annals of oncology: official journal of the European Society for Medical Oncology. 2013;24(6):1434-43.

11. Forat-Yazdi M, Neamatzadeh H, Sheikhha MH, Zare-Shehneh M, Fattahi M. BRCA1 and BRCA2 common mutations in Iranian breast cancer patients: a meta-analysis. Asian Pacific journal of cancer prevention: APJCP. 2015;16(3):1219-24.

12. Neamatzadeh H, Shiryazdi SM, Kalantar SM. BRCA1 and BRCA2 mutations in Iranian breast cancer patients: A systematic review. Journal of research in medical sciences: the official journal of Isfahan University of Medical Sciences. 2015;20(3):284-93.

13. Kamali M, Kargar S, Heiranizadeh N, Zare M, Kargar S, Zare Shehneh M, et al. Lack of an Association between the Hogg1 Ser326Cys Polymorphism and Breast Cancer Risk: a Systematic Review And Meta-Analysis Of 18 Studies. Asian Pacific journal of cancer prevention: APJCP. 2017;18(1):245-51.

14. Salehi A, Zeraati H, Mohammad K, Mahmoudi M, Talei AR, Ghaderi A, et al. Survival of male breast cancer in Fars, South of Iran. Iranian Red Crescent medical journal. 2011;13(2):99-105.

15. Amirifard N, Sadeghi E. Breast Cancer in Men: a Report from the Department of Radiation Oncology in Kermanshah Province, Iran. Asian Pacific journal of cancer prevention: APJCP. 2016;17(5):2593-6.

16. Yalaza M, Inan A, Bozer M. Male Breast Cancer. Journal of breast health (2013). 2016;12(1):1-8.

17. Giordano SH, Perkins GH, Broglio K, Garcia SG, Middleton LP, Buzdar AU, et al. Adjuvant systemic therapy for male breast carcinoma. Cancer. 2005;104(11):2359-64.

18. Shah S, Bhattacharyya S, Gupta A, Ghosh A, Basak S. Male breast cancer: a clinicopathologic study of 42 patients in eastern India. Indian journal of surgical oncology. 2012;3(3):245-9.

19. Soliman M HM. Male breast cancer: a clinicopathological study of an Egyptian population (Alexandria experience). Contemp Oncol (Pozn). 2016;. 335-40. p.

20. Cutuli B, Le-Nir CC, Serin D, Kirova Y, Gaci Z, Lemanski $\mathrm{C}$, et al. Male breast cancer. Evolution of treatment and prognostic factors. Analysis of 489 cases. Critical reviews in oncology/hematology. 2010;73(3):246-54.

21. Yoney A, KucukA, Unsal M. Male breast cancer: a retrospective analysis. Cancer radiotherapies : Journal de la Societe Francaise de radiotherapes oncologique. 2009;13(2):103-7.

22. Choi MY LS, Lee JE, Park HS, Lim ST, Jung Y, et al. Characterization of Korean Male Breast Cancer Using an Online Nationwide Breast-Cancer Database: Matched-Pair Analysis of Patients with Female Breast Cancer. Medicine (Baltimore). 2016;. e3299. p.

23. Zeinalian M HN, Naji H, Salehi R, Hashemzadeh-Chaleshtori M. Clinicopathological Analysis of Patients with Breast Cancer and Their Families. IJBC. 2016; 17-22. p.

24. Anderson WF, Jatoi I, Tse J, Rosenberg PS. Male breast cancer: a population-based comparison with female breast cancer. Journal of clinical oncology: official journal of the American Society of Clinical Oncology. 2010;28(2):232-9.

25. Landero J, Touloei K, Glick BP. Invasive ductal breast carcinoma underneath a lipoma in a male patient. The Journal of clinical and aesthetic dermatology. 2012;5(10):33-7.

26. Hill A, Yagmur Y, Tran KN, Bolton JS, Robson M, Borgen PI. Localized male breast carcinoma and family history. An analysis of 142 patients. Cancer. 1999;86(5):821-5.

27. Hong JH, Ha KS, Jung YH, Won HS, An HJ, Lee GJ, et al. Clinical Features of Male Breast Cancer: Experiences from Seven Institutions Over 20 Years. Cancer research and treatment: official journal of Korean Cancer Association. 2016;48(4):1389-98.

28. Costantini M, Fassio T, Canobbio L, Landucci M, Resasco $\mathrm{M}$, Boccardo F. Role of blood groups as prognostic factors in primary breast cancer. Oncology. 1990;47(4):308-12.

29. Miao SY, Zhou W, Chen L, Wang S, Liu XA. Influence of $\mathrm{ABO}$ blood group and Rhesus factor on breast cancer risk: a meta-analysis of 9665 breast cancer patients and 244,768 controls. Asia-Pacific journal of clinical oncology. 2014;10(2):101-8

30. Masci G CM, Caruso F, Salvini P, Carnaghi C, Giordano $\mathrm{L}$, et al Clinicopathological and Immunohistochemical Characteristics in Male Breast Cancer: A Retrospective Case Series. Oncologist. (2015). 586-92. p. 
31. Nahleh Z, Girnius S. Male breast cancer: a gender issue. Nature clinical practice Oncology. 2006;3(8):428-37.

32. Yazdi MF, Rafieian S, Gholi-Nataj M, Sheikhha MH, Nazari T, Neamatzadeh H. CYP2D6 Genotype and Risk of Recurrence in Tamoxifen Treated Breast Cancer Patients. Asian Pacific journal of cancer prevention : APJCP. 2015;16(15):6783-7.

\section{(ब) 0 (}

This work is licensed under a Creative Commons AttributionNon Commercial 4.0 International License. 